\title{
Effect of fiber orientation on the mechanical properties of laminated polymer composites
}

\begin{abstract}
This article presents a review and proof of concept through experiment of the general idea of the effect of fiber orientation on the tensile properties of laminated polymer composites. The research methodology includes the fabrication of woven fabric glass epoxy composite laminates with 90,60 , and $45^{\circ}$ orientation. The mechanical testing was conducted through a tensile machine. It was found that the maximum load, the ultimate tensile strength (UTS), the Young's modulus, and the modulus of toughness were the highest in the sample with $90^{\circ}$ orientation. While the maximum load and ultimate tensile strength are lowest in $60^{\circ}$ orientation and the Young's modulus and also the modulus of toughness are lowest in $45^{\circ}$ orientation. As a conclusion, the orientation plays an important role in determining the optimum property for each application.
\end{abstract}

Keyword: Composite; Fiber orientation; Mechanical property 